\title{
Expanding controlled donation after the circulatory determination of death: stronger emphasis on different cultural, religious and legal backgrounds is needed
}

\author{
Thomas Müller ${ }^{1^{*}}\left(\mathbb{D}\right.$, Daniel Brodie ${ }^{2}$, Roberto Lorusso ${ }^{3}$, Graeme MacLaren $^{4}$ and Shingo Ichiba ${ }^{5}$
}

(0) 2021 The Author(s)

Dominguez-Gil and colleagues have presented a very important statement with the intent to expand controlled donation of organs after the circulatory determination of death (cDCDD) [1]. It summarizes the necessary preconditions and the process of withdrawing life-sustaining treatment exceptionally well. Specific relevance is given to the current practice of perfusion and repair of organs after cDCDD. Acknowledging both the importance and strengths of the statement, we nonetheless are convinced that the approach to encouraging further use of CDCDD requires a stronger emphasis on differing cultural, religious and legal backgrounds around the globe.

As a hallmark of mature societies, elaborate rituals and customs around the time of dying have developed. These are critically important to soothe the deep sorrow of those who remain behind. Spending time with the dying patient among close family members in quiet, peaceful surroundings is an essential element of these conventions. By introducing cDCDD as the "normal" process of dying in an intensive care unit, the extant culture will be fundamentally changed. A tranquil atmosphere is not possible if the deceased must be promptly cannulated for extra corporeal membrane oxygenation (ECMO) or rushed to the operating room to retrieve organs in time. Establishing this as a new norm may have unpredictable effects on grieving family members and upon society at large, particularly if these principles are also extended to

\footnotetext{
*Correspondence: thomas.mueller@klinik.uni-regensburg.de

${ }^{1}$ Department of Internal Medicine II, University Hospital Regensburg, Regensburg, Germany
}

Full author information is available at the end of the article dying children. cDCDD programs have been established in many pediatric institutions but have understandably generated considerable controversy [2].

The expert panel states that the existing evidence is insufficient to determine how long circulation must be arrested before brain function is irreversibly lost. Therefore, for thoraco-abdominal normothermic regional perfusion (TA-NRP), a rapid sternotomy is performed and the supra-aortic vessels are clamped to immediately stop cerebral perfusion. Yet, the procedure is not well established, as recently "a refinement to current protocols has been proposed to ensure that circulation to the brain through collateral circulation does not occur" $[1,3]$. With only "eight heart transplant procedures... in the world with the use of TA-NRP without ex situ machine perfusion" [1], the experience with this specific procedure is insufficient, and many questions remain unresolved. We do not support the proposal that TA-NRP without ex situ machine perfusion should be adopted by countries to make heart transplantation economically feasible.

The authors appeal to the World Health Organization (WHO) Task Force on Organ Donation and Transplantation to review and endorse their statement to all member states. The WHO encompasses countries from around the world, with vastly different cultural, religious and legal requirements. While the expert panel of this statement was international, it was still very much influenced by Western cultures, and lacked representation from Asia, Africa and Latin America. Western cultures tend to be influenced by utilitarian ethical theories, which in principle demand that we consider the interests of all humans equally. The view that seeks to maximize

\section{Springer}


the utility of a corpse, even where it would be in the interest of helping others, yet potentially ignoring the dignity of dying, may not be shared by all cultures.

\section{Author details}

${ }^{1}$ Department of Internal Medicine II, University Hospital Regensburg, Regensburg, Germany. ${ }^{2}$ Department of Medicine and Center for Acute Respiratory Failure, Columbia University College of Physicians and Surgeons/ New York-Presbyterian Hospital, New York, NY, USA. ${ }^{3}$ Heart \& Vascular Centre, Maastricht University Medical Centre, Cardiovascular Research Institute Maastricht (CARIM), Maastricht University, MUMC+), Maastricht, The Netherlands. ${ }^{4}$ Department of Cardiac, Thoracic and Vascular Surgery, Cardiothoracic ICU, National University Health System, Singapore, Singapore. ${ }^{5}$ Department of Clinical Engineering and Department of Intensive Care Medicine, Tokyo Women's Medical University Hospital, Tokyo, Japan.

\section{Funding}

Open Access funding enabled and organized by Projekt DEAL.

\section{Declarations}

\section{Conflicts of interest}

All authors declare that they have no conflict of interest.

\section{Open Access}

This article is licensed under a Creative Commons Attribution-NonCommercial 4.0 International License, which permits any non-commercial use, sharing, adaptation, distribution and reproduction in any medium or format, as long as you give appropriate credit to the original author(s) and the source, provide a link to the Creative Commons licence, and indicate if changes were made. The images or other third party material in this article are included in the article's
Creative Commons licence, unless indicated otherwise in a credit line to the material. If material is not included in the article's Creative Commons licence and your intended use is not permitted by statutory regulation or exceeds the permitted use, you will need to obtain permission directly from the copyright holder. To view a copy of this licence, visit http://creativecommons.org/licen ses/by-nc/4.0/.

\section{Publisher's Note}

Springer Nature remains neutral with regard to jurisdictional claims in published maps and institutional affiliations.

Accepted: 5 April 2021

Published online: 27 April 2021

\section{References}

1. Dominguez-Gil B, Ascher N, Capron AM et al (2021) Expanding controlled donation after the circulatory determination of death: statement from an international collaborative. Intensive Care Med 47:265-281

2. Carcillo JA, Orr B, Bell M et al (2010) A call for full public disclosure and moratorium on donation after cardiac death in children. PediatrCrit Care Med 11:641-643

3. Manara A, Shemie SD, Large S et al (2020) Maintaining the permanence principle for death during in situ normothermic regional perfusion for donation after circulatory death organ recovery: a United Kingdom and Canadian proposal. Am J Transplant 20(8):2017-2025 